\title{
Gambaran Morfologi Spermatozoa pada Perokok Sedang di Lingkungan PE Group yang Datang ke Bagian Biologi Fakultas Kedokteran Universitas Andalas
}

\author{
Vinda Dwi Apriora ${ }^{1}$, Arni Amir $^{2}$, Oea Khairsyaf ${ }^{3}$
}

\begin{abstract}
Abstrak
Tingginya angka pria perokok di seluruh dunia dan fakta bahwa asap rokok mengandung lebih dari 4000 bahan berbahaya yang dapat mengganggu sistem reproduksi. Gangguan yang terjadi dapat berupa penurunan kualitas spermatozoa yang dapat dilihat melalui analisis sperma. Tujuan penelitian ini adalah untuk melihat gambaran morfologi spermatozoa pada Perokok sedang di Lingkungan PE Group. Ini merupakan penelitian deskriptif dari September 2012 hingga 2013, menggunakan metode total sampling sebanyak 33 pria perokok yang mendatangi Laboratorium Biologi Fakultas Kedokteran Universitas Andalas Padang. Parameter kelainan morfologi spermatozoa (teratozoospermia) diukur menurut kriteria WHO yaitu apabila jumlah sperma dengan bentuk normal yang dicacah $\geq$ $30 \%$. Semua sampel menunjukkan hasil yang normal. Kesimpulan hasil penelitian ini adalah perokok sedang yang diteliti memiliki gambaran morfologi spermatozoa yang normal, dengan abnormalitas kepala sebagai abnormalitas terbanyak dan bentuk kelainan kepala besar sebagai bentuk kelainan yang paling banyak ditemukan.
\end{abstract}

Kata kunci: rokok sigaret, analisis sperma, morfologi sperma, teratozoospermia

\section{Abstract}

The large number of men worldwide smoke and the fact that cigarette smoke contains detriment substances that can affect the health holistically and especially fertility it self is the main reason. It contains more than four thousands of detrimental substances for instance oxidants, carcinogenic and mutagenic agents. The objective of this study was to evaluate sperm parameters especially it's morphology among medium smokers in PE Group, Itd. In this descriptive study, started from September 2012 until 2013. A total of thirty three males who were classified as medium smokers were enrolled to Biology Laboratory Medical Faculty of Andalas University Padang. Teratozoospermia parameters were measured according to the World Health Organization criteria and Biology Infertility Division's in which the normal Sperm morphology counts $\geq 30 \%$. All of samples showed normal results, with the sperm-head abnormality as the major abnormality. The conclusions is all participants showed normal spermatozoa morphology counts and the head abnormality is the major detriments.

Keywords: cigarette smoking, sperm analyzing, sperm morphology, teratozoospermia

Affiliasi penulis :1.Pendidikan dokter FK UNAND (Fakultas Kedokteran Universitas Andalas Padang), 2. Bagian Biologi FK UNAND, 3. Bagian Paru FK UNAND/RS Dr. M. Djamil

Korespondensi :Vinda Dwi Apriora, E-mail : vzulkifli@gmail.com,

Telp: +6281270993366

\section{PENDAHULUAN}

Rokok adalah hasil olahan tembakau terbungkus termasuk cerutu atau bentuk lainnya yang dihasilkan dari tanaman Nicotiana tobacum, Nicotiana rustica dan spesies lain. Bentuk sintetis yang mengandung nikotin dan tar dengan atau tanpa bahan tambahan Sebatang rokok tembakau mengandung lebih dari 4000 bahan kimia berbahaya di dalamnya. Dari ribuan kandungan zat pada rokok itu, tiga kandungan yang paling berbahaya adalah tar, nikotin dan karbon monoksida. ${ }^{1}$

Diperkirakan sekitar 1,3 milyar penduduk dunia adalah perokok, $80 \%$ diantaranya berada di Negara 
berkembang. Berdasarkan Data WHO, total jumlah perokok di Indonesia menempati peringkat ketiga setelah China dan India, dengan angka 34,7\% dari total jumlah penduduk atau sekitar 82 juta jiwa. ${ }^{2}$

Impotensi disebabkan oleh efek vasokonstriksi dari nikotin. Nikotin bekerja sebagai vasokonstriktor yang menyempitkan lumen pembuluh darah sehingga menginduksi terjadinya lesi atherosklerotik. Lesi atherosklerotik yang terjadi pada pembuluh darah daerah di daerah pelvis akan menyebabkan terjadinya perlambatan aliran darah ke penis, sedangkan untuk dapat ereksi dibutuhkan pasokan aliran darah yang adekuat ke penis. $^{3}$

Efek vasokonstriktor dari nikotin juga dapat mengakibatkan keadaan iskemik pada penis, yang juga mengakibatkan abnormalitas dari morfologi spermatozoa. Abnormalitas dari spermatozoa mencakup abnormalitas kepala, abnormalitas leher, dan abnormalitas ekor. ${ }^{4}$

Pada perokok juga dapat ditemukan penurunan kadar testosteron. Hal ini akan mengganggu proses spermatogenesis karena spermatogenesis berjalan dibawah pengaruh dari testosteron. Sehingga pada tahap pematangan spermatid menjadi spermatozoa matur, dapat terjadi gangguan yang dapat mempengaruhi morfologi normal.

Kerusakan pada morfologi spermatozoa serta motilitas juga dapat menurunkan 40\% kesempatan untuk dapat hamil secara alamiah pada pasangan si perokok tersebut. Sehingga pengaruh rokok terhadap morfologi spermatozoa semakin penting untuk dikaji lebih lanjut. ${ }^{5}$

\section{METODE}

Rancangan penelitian ini bersifat penelitian deskriptif dengan desain penelitian retrospektif dengan tujuan melihat gambaran morfologi spermatozoa pada Perokok Sedang pria di Lingkungan PE Group yang datang ke Laboratorium Biologi Fakultas Kedokteran Universitas Andalas. Penelitian ini mulai dilaksanakan pada Bulan September 2012 di Laboratorium Biologi Fakultas Kedokteran Universitas Andalas Padang.

Populasi penelitian adalah perokok aktif sedang pria di Lingkungan PE Group yang berusia 20-50 tahun. Teknik pengambilan sampel yang dipilih yaitu dengan metode total sampling yaitu semua partisipan yang tergolong perokok sedang di Lingkungan $P E$ Group yang datang ke Bagian Biologi FK Unand. Subjek penelitian adalah yang memenuhi kriteria inklusi: pria dengan usia 20 - 50 tahun, tergolong perokok sedang berdasarkan Indeks Brinkman, bersedia dan berdomisili di Padang.

Alat dan bahan penelitian ini meliputi semen yang diambil setelah abstinensia seksual selama sedikitnya 48 jam dan tidak lebih lama dari tujuh hari. Gelas kaca bermulut lebar (gelas arloji), Pipet leukosit, Object glass dan deck glass, mikroskop, reagensia (larutan Giemsa).

HASIL

Tabel 1. Persentase morfologi spermatozoa normal

\begin{tabular}{lll}
\hline $\begin{array}{c}\text { Morfologi } \\
\text { Spermatozoa }\end{array}$ & & Indeks Teratozoospermia \\
\hline Normal & $\mathrm{f}$ & $\%$ \\
Abnormal & 33 & 100 \\
Total & 0 & 0 \\
& 33 & 100
\end{tabular}

Berdasarkan Tabel 1, seratus persen sampel memiliki gambaran morfologi spermatozoa yang normal berdasarkan yang didapatkan. Sampel digolongkan normal apabila $\geq 30 \%$.

Dalam penelitian ini, rerata persentase spermatozoa normal adalah sebesar $49,2 \%$, dan rerata persentase spermatozoa abnormal 50,8\%.

Spermatozoa terdiri dari 3 bagian utama meliputi kepala, leher dan ekor. Ketiganya dapat mengalami kelainan/abnormalitas seperti dijabarkan pada Tabel 2 berikut.

Tabel 2. Jenis kelainan spermatozoa abnormal

\begin{tabular}{lccc}
\hline $\begin{array}{c}\text { Morfologi } \\
\text { Spermatozoa }\end{array}$ & Maks & Min & Rerata \\
\hline Kepala & 41 & 15 & 30.2 \\
Ekor & 32 & 3 & 14.9 \\
Leher & 10 & 2 & 5.7 \\
\hline
\end{tabular}

Berdasarkan Tabel 2, terlihat $50,8 \%$ rerata abnormalitas morfologi spermatozoa,. Kelainan Kepala merupakan jenis abnormalitas yang paling banyak ditemukan, disusul dengan kelainan ekor, dan kelainan 
leher yang paling sedikit ditemukan. Bentuk kelainan spermatozoa dapat dilihat seperti pada tabel berikut.

Tabel 3. Bentuk kelainan kepala spermatozoa

\begin{tabular}{lccc}
\hline \multicolumn{1}{c}{$\begin{array}{c}\text { Bentuk } \\
\text { Kelainan }\end{array}$} & Maks & Min & Rerata \\
\hline Amorf & 3 & 0 & 0.7 \\
Besar & 26 & 9 & 16.3 \\
Pin & 4 & 0 & 1.7 \\
Rongga & 2 & 0 & 0.7 \\
Ganda & 5 & 0 & 2.3 \\
Lisong & 4 & 0 & 2 \\
Kecil & 12 & 3 & 7.1 \\
\hline
\end{tabular}

Berdasarkan Tabel 3 terlihat bahwa bentuk kelainan kepala meliputi kepala amorf, kepala besar (25\% > kepala normal), pin-headed (seperti jarum), berongga (> $20 \%$ dari daerah kepala ditempati oleh daerah berongga yang tidak terpulas), kepala ganda, berbentuk lisong (tapering), kepala kecil (25\% < kepala normal), atau bentuk kombinasi. Spermatozoa dengan kepala besar merupakan bentuk kelainan yang paling banyak ditemukan.

Tabel 4. Bentuk ekor kelainan spermatozoa

\begin{tabular}{lccc}
\hline & \multicolumn{3}{c}{ Abnormalitas Ekor } \\
$\begin{array}{l}\text { Bentuk } \\
\text { Kelainan }\end{array}$ & Maks & Min & Rerata \\
\hline Pendek & 9 & 0 & 4 \\
Ganda & 7 & 2 & 4 \\
Patah & 8 & 0 & 3.3 \\
Gulung & 7 & 0 & 2.5 \\
Tetesan & 4 & 0 & 1.1 \\
\hline
\end{tabular}

Berdasarkan Tabel 4 dapat terlihat bahwa bentuk kelainan morfologi ekor spermatozoa meliputi ekor pendek, ganda, patah, ekor tergulung atau ekorekor dengan tetesan pada ujungnya, atau kombinasi dari berbagai kelainan tersebut. Spermatozoa dengan bentuk ekor pendek dan ekor ganda merupakan kelainan paling banyak ditemukan.
Tabel 5. Bentuk kelainan leher spermatozoa

\begin{tabular}{lccc}
\hline & \multicolumn{3}{c}{ Abnormalitas Leher/Bagian Tengah } \\
$\begin{array}{l}\text { Bentuk } \\
\text { Kelainan }\end{array}$ & Maks & Min & Rerata \\
\hline Bengkak & 8 & 1 & 3.9 \\
Tipis & 4 & 0 & 1.8 \\
\hline
\end{tabular}

Berdasarkan Tabel 5 dapat terlihat bahwa bentuk kelainan morfologi leher spermatozoa meliputi bagian tengah yang membengkak/ireguler/bengkok, atau juga secara abnormal bagian tengah tipis. Bentuk kelainan leher membengkak merupakan yang paling banyak ditemukan.

\section{PEMBAHASAN}

Penelitian ini dilakukan untuk melihat gambaran morfologi spermatozoa pada perokok sedang di Lingkungan PE Group yang datang ke Bagian Biologi FK Unand. Sampel pada penelitian ini sebanyak 33 orang. Penelitian ini mendapatkan hasil bahwa dari ke tiga puluh tiga sampel yang diteliti, sebanyak 33 sampel (100\%) memiliki morfologi spermatozoa normal.

Pada setiap mililiter ejakulat yang dikeluarkan, terkandung lebih kurang 20 juta spermatozoa. Persentase morfologi spermatozoa normal ditentukan dengan mencacah secara acak 100 spermatozoa secara mikroskopis. Dalam setiap sediaan sampel normal, selalu akan ditemukan spermatozoa dengan abnormalitas tertentu, tetapi jumlah spermatozoa abnormal tersebut harus $<70 \%$. Dengan kata lain jumlah spermatozoa normal harus $\geq 30 \%$. Dalam penelitian ini, rerata persentase spermatozoa normal adalah sebesar $49,2 \%$ dan rerata persentase spermatozoa abnormal $50,8 \%$.

Spermatozoa abnormal adalah spermatozoa dengan ciri morfologi diluar batas normal. Spermatozoa dikatakan normal bila memiliki memiliki struktur kepala, ekor, dan leher yang normal. Kepala normal memiliki rasio antara panjang dengan lebar 1,5-1,75; leher merupakan bagian sempit yang menghubungkan antara kepala dan ekor; ekor kurang lebih 9 kali panjang kepala sperma yang terbagi 3 
bagian, yaitu principle piece, middle piece dan end piece. $^{4}$

Morfologi merupakan salah satu faktor penting yang diperlukan dalam menunjang kemampuan fertilisasi spermatozoa. Fertilisasi akan terjadi apabila spermatozoa memiliki bentuk yang normal. Hanya spermatozoa normal yang mampu membuahi sel telur. Walaupun jumlah spermatozoa seseorang normal, namun apabila morfologinya terganggu akan berpengaruh terhadap rendahnya kemampuan fungsional spermatozoa. ${ }^{6}$

Tabel 1 menggambarkan 33 sampel (100\%) memiliki gambaran morfologi spermatozoa yang normal. Sejalan dengan beberapa penelitian lain yang menyatakan bahwa tidak terdapat pengaruh merokok terhadap morfologi. Penelitian lain menunjukkan bahwa tidak ada perbedaan yang berarti antar perokok dengan bukan perokok dalam konsentrasi sperma, karakteristik pergerakan sperma, morfologi dan motilitas. Volume semen merupakan satu-satunya parameter yang menunjukkan adanya pengaruh merokok terhadap kualitas spermatozoa. ${ }^{7}$

Penelitian yang melihat efek yang disebabkan nikotin dan kotinin, bukan penyebab penurunan morfologi, $\mathrm{pH}$ dan motilitas seperti yang sering dilaporkan literatur. Hal ini membuktikan bahwa nikotin yang sering disebut sebagai penyebab penurunan morfologi masih menjadi perdebatan. Sehingga sampai saat ini mekanisme pasti rokok yang mempengaruhi morfologi spermatozoa secara pasti masih dalam penelitian. ${ }^{8}$

Penelitian tentang analisis semen dari 1683 partisipan berdasarkan kriteria MSOME, didapatkan bahwa, parameter tunggal, dalam hal ini merokok, tidak adekuat dalam mempengaruhi kualitas sperma individu. Dibutuhkan kombinasi dari berbagai faktor seperti konsumsi alkohol, usia, indeks massa tubuh, stress, konsumsi kopi, frekuensi ejakulasi per bulan, serta durasi abstinensia seksual. ${ }^{9}$

Tabel 3 memperlihatkan abnormalitas kepala adalah abnormalitas yang paling banyak ditemukan yaitu sebanyak $30,2 \%$. Bentuk kelainan paling banyak ditemukan adalah permatozoa dengan kepala besar. Berdasarkan Tabel 4, abnormalitas ekor adalah abnormalitas ke-2 terbanyak ditemukan sebesar
$14,1 \%$. Bentuk kelainan paling banyak ditemukan adalah spermatozoa ekor pendek.

Berdasarkan tabel 5 abnormalitas leher dan bagian tengah adalah abnormalitas yang paling sedikit ditemukan sebanyak 5,73\%. Bentuk kelainan paling banyak ditemukan adalah leher bengkak.

\section{KESIMPULAN}

Semua sampel spermatozoa perokok sedang di Lingkungan PE Group yang datang ke Bagian Biologi FK UA memiliki Morfologi Spermatozoa yang normal.

Jenis abnormalitas morfologi spermatozoa pada perokok sedang terbanyak ditemukan adalah abnormalitas kepala. Bentuk kelainan kepala spermatozoa pada perokok sedang terbanyak ditemukan adalah kepala besar. Bentuk kelainan ekor spermatozoa pada perokok sedang terbanyak ditemukan adalah ekor pendek dan ekor ganda. Bentuk kelainan leher dan bagian tengah pada perokok sedang terbanyak ditemukan adalah leher bengkak.

\section{UCAPAN TERIMA KASIH}

Penulis mengucapkan terima kasih kepada seluruh partisipan dan staff Bagian Biologi Fakultas Kedokteran Universitas Andalas Padang sebagai tempat penelitian atas fasilitas yang telah diberikan.

\section{DAFTAR PUSTAKA}

1. Pemerintah Republik Indonesia. Peraturan Pemerintah Republik Indonesia No. 19 Tahun 2003 Tentang Pengamanan Rokok Bagi Kesehatan Bab 1 Pasal 1 Poin 1. Jakarta.2003.

2. World Health Organization.Tobacco (diunduh 22 April 2013). Tersedia dari: URL: HYPERLINK http://www.who.int

3. John GS, Ronny B, John S, Joseph C. K. P-468: Erectile dysfunction and smoking among men with hypertension in primary care. Am $\mathrm{J}$ Hypertens. 2001;14 (S1): 188A.

4. World Health Organization. WHO laboratory manual for the examination of human semen and sperm-cervical mucus interaction. 4th ed. Cambridge: Cambridge University Press; 1999. 
5. Anton DW. Morfologi Spermatozoa. 2009 (diunduh 22 April 2013). Tersedia dari: URL: HYPERLINK http://www.klinikandrologi.com

6. Heni S. Kesesuaian hasil pemeriksaan morfologi spermatozoa antara pulasan giemsa, meyer, dan o.steeno dari pria pasangan usia subur. The Journal of Andrology Indonesia. 2011;8(38):12-8.

7. Fábio FP, Bernardo PS, Jorge $H$, Eleonora BP, Antônio ML. Cigarette smoking is related to a decrease in semen volume in a population of fertile men. BJU Int. Sao Paulo. 2006;97(2):324-6.
8. Seyed GAJ, Hiroaki S, Ayustawati, Yuki H, Yasuko $\mathrm{S}$, Ali $\mathrm{K}$, et al. The in-vitro effects of nicotine, cotinine and leptin on sperm parameters analyzed by CASA system. Iranian Journal of Reproductive Medicine. 2008;6(3):157-65.

9. Johannes W, Barbara W, Astrid S, Pierre V, Anton $\mathrm{N}$, Dietmar S, et al. The Combination matters distinct impact of lifestyle factors on sperm quality: a study on semen analysis of 1683 patients according to MSOME criteria. Journal of Reproductive Biology and Endocrinology Austria. 2012. 